\title{
A RESPONSABILIDADE CIVIL AMBIENTAL COMO EXPRESSÃO DA JUSTIÇA DISTRIBUTIVA: UM ESTUDO ACERCA DA MUDANÇA DE PARADIGMA FILOSÓFICO DA RESPONSABILIDADE CIVIL
}

\author{
Gabriel Santos Lima ${ }^{1}$ \\ João Daniel Macedo Sá ${ }^{2}$ \\ Filipe Augusto Oliveira Rodrigues ${ }^{3}$
}

\begin{abstract}
RESUMO
O presente artigo aborda a responsabilidade civil ambiental brasileira, para avaliar se a adoção da teoria objetiva promoveu mudanças em seus pressupostos filosóficos. Para alcançar tal objetivo, inicialmente apresenta-se a matriz clássica da responsabilidade, de orientação formalista e pautada na justiça corretiva. Em seguida, analisa-se se o instituto jusprivatista passou a se vincular a parâmetros distributivos. A metodologia do trabalho baseou-se em pesquisa teórica, com levantamento bibliográfico. Para justificar e argumentar sobre as hipóteses foi utilizado o método dedutivo. A conclusão defende que a responsabilização civil ambiental adota um modelo de aplicação pautado eminentemente em critérios de justiça distributiva.
\end{abstract}

PALAVRAS-CHAVE: RESPONSABILIDADE CIVIL AMBIENTAL; JUSTIÇA CORRETIVA; JUSTIÇA DISTRIBUTIVA; TEORIA OBJETIVA; FILOSOFIA DO DIREITO PRIVADO.

\section{ENVIRONMENTAL CIVIL LIABILITY AS AN EXPRESSION OF DISTRIBUTIVE JUSTICE: A STUDY ON THE PHILOSOPHICAL CHANGE ON CIVIL LIABILITY PARADIGMS}

\section{ABSTRACT}

This article deals with Brazilian environmental civil liability, to assess whether the adoption of the objective theory promoted changes in its philosophical assumptions. To achieve this goal, the classic matrix of responsibility is presented, with a formalistic orientation and based on corrective justice. Then, it is analyzed if this private institute started to be linked to distributive parameters. The methodology of the work was based on theoretical research, with bibliographic survey. The deductive method was used to justify and argue about the

\footnotetext{
${ }^{1}$ Mestrando em Direito pelo Programa de Pós-Graduação em Direito da Universidade Federal do Pará (PPGD/UFPA). Graduado em Direito pela Universidade Federal do Pará, com período de mobilidade acadêmica internacional na Faculdade de Direito da Universidade de Lisboa (ULisboa). Membro do Grupo de Pesquisa Teoria do Direito, Meio Ambiente e Justiça (http://dgp.cnpq.br/dgp/espelhogrupo/228885). Contato: gabrielsantoslima@live.com.

${ }^{2}$ Doutor em Direito pela Universidade Federal do Pará. Advogado. Professor adjunto da UFPA. É membro do corpo docente permanente do Programa de Pós-Graduação em Direito da UFPA e membro da Comissão de Meio Ambiente da OAB/PA. Coordenador do Grupo de Pesquisa Teoria do Direito, Meio Ambiente e Justiça (http://dgp.cnpq.br/dgp/espelhogrupo/228885). Contato: joaosa@ufpa.br.

${ }^{3}$ Doutorando em Direito pelo Programa de Pós-Graduação em Direito da Universidade Federal do Pará (PPGD/UFPA). Mestre em Direito pela Universidade Federal do Pará. É professor de História do Direito, Filosofia do Direito e Introdução ao Estudo do Direito do Centro Universitário do Estado do Pará. Coordenador do Grupo de Pesquisa Pura Teoria do Direito (CESUPA) e membro do Grupo de Pesquisa Teorias Normativas (UFPA). Contato: filipeaorodrigues@ gmail.com.
} 
hypotheses. The conclusion argues that environmental civil liability adopts an application model based on criteria of distributive justice.

KEYWORDS: ENVIRONMENTAL CIVIL LIABILITY; CORRECTIVE JUSTICE; DISTRIBUTIVE JUSTICE; OBJECTIVE THEORY; PHILOSOPHY OF PRIVATE LAW. 1 INTRODUÇÃO

Este artigo tem como função precípua analisar os fundamentos do atual debate filosófico sobre os pressupostos da responsabilidade civil ambiental, apresentando contextualização teórica especialmente relevante no contexto anglo-saxão, mas que cada vez mais é discutida no cenário brasileiro. Nesse sentido, analisar os pontos de incidência das teorias do direito privado e, por conseguinte, das teorias da justiça, torna-se tarefa essencial para o correto dimensionamento dos termos propostos pelo direito dos danos na seara ambiental. Assim, apresentaremos os termos de filosofia do direito privado, mensurando especificamente a reparação dos bens ambientais ${ }^{4}$, o modelo de responsabilização, e os possíveis caminhos teóricos clássicos (e atuais) que permeiam o debate.

Como se sabe, o mecanismo de proteção em face de uma eventual lesão ambiental ${ }^{5}$ se materializa na realidade brasileira de três formas: a) administrativa; b) penal, e; c) civil. A responsabilidade civil, abordagem que se almeja no presente trabalho, não obstante classicamente tenha função reparatória em face de um evento danoso, vem cedendo, nos debates atuais a uma função preventiva e, até mesmo, punitiva.

Na medida em que atue na reparação de um modelo de bem jurídico em grande medida difuso, coletivo e transindividual, a responsabilidade civil vai ser decisiva na justiça do caso concreto, especialmente pela atribuição de deveres jurídicos sucessivos ao responsável pelo dano. Diante de uma consistente discussão, especialmente em common law, sobre os pressupostos de teoria do direito privado, há também uma sólida e proeminente reunião de autores latino-americanos no sentido de fornecer reflexões filosóficas sobre os

\footnotetext{
${ }^{4} \mathrm{Na}$ esfera normativa, o meio ambiente, conforme os ditames estabelecidos pela Constituição Cidadã de 1988, é bem de uso comum do povo essencial à qualidade de vida. Enquanto bem público, pode ser enquadrado na dualidade de regimes (público e privado) apontados por Benatti, Brito, Carames e Belucio (2018, p. 90).

${ }^{5}$ Para contextualizar esse cenário, temos que o sistema de responsabilidade ambiental está intimamente atrelado a uma tendência global de proteção ao meio ambiente, que culminou em larga medida numa considerável inserção, no último meio século, de conceitos e mecanismos de proteção em vários diplomas normativos (AMADO, 2019, p. 25). Não obstante a ampliação dos mecanismos de tutela, a degradação ambiental avança gradativamente no contexto local e diversos são os exemplos na história de enormes desastres ambientais. A repercussão constitucional do meio ambiente ecologicamente equilibrado prospecta uma obrigação de cuidado tanto por parte do Poder Público, como da coletividade, o que na visão de Milaré (2018, p. 180-181), justifica seu enquadramento como direito fundamental, de terceira dimensão, de natureza transindivual e difusa.
} 
mais diversos institutos de direito privado, incluindo a responsabilidade civil, que repercutem de modo relevante sobre diversos ramos mais recentes no cenário jurídico global, como o direito do consumidor e o direito ambiental. Por sua vez, igualmente relevante atentar ao posicionamento dos tribunais no centro de suas formulações e argumentações de questões afetas à responsabilidade civil, que vão ser cruciais para o estabelecimento de uma teoria do direito privada aplicável na realidade brasileira.

É nesse contexto que a investigação se faz relevante, uma vez que os termos clássicos da responsabilidade civil extracontratual precisam oferecer uma explicação condizente com os pressupostos jurídicos atuais e a consagração de princípios estabelecidos por autores ao longo da história da teoria do direito privado. O presente trabalho vislumbra a possibilidade de fornecer argumentos indicativos de que os padrões da responsabilidade civil ambiental vão além da mera reparação (reequilíbrio) de um injusto entre duas partes, especialmente quando se vulnera bens ambientais, que têm repercussão que notadamente extrapolam limites inter partes.

O problema da pesquisa se traduz pela seguinte indagação: em que medida a responsabilidade civil ambiental guarda coerência com os pressupostos da teoria do direito privado?

O objetivo geral da pesquisa consiste em analisar quais os pressupostos teóricos de aplicação da teoria do direito privado no âmbito da responsabilidade civil ambiental. Os objetivos específicos consistem em: analisar se a aplicação da responsabilidade civil no contexto dos danos ambientais tende a seguir critérios de justiça corretiva e formalistas ou de justiça distributiva e funcionalistas, e; verificar em que racionalidade reside a aplicação da responsabilidade civil ambiental.

Para alcançar tal objetivo, metodologia do trabalho baseou-se em pesquisa teórica, com levantamento bibliográfico. Para justificar e argumentar sobre as hipóteses levantadas foi utilizado o método dedutivo.

A primeira seção trata da responsabilidade civil no contexto da filosofia do direito privado dominante no mundo ocidental após a modernidade. Logo, se apresenta a filosofia da responsabilidade como aquela que funciona por critérios formalistas, ou seja, internos ao sistema de responsabilidade e de justiça corretiva. A segunda seção analisa a tese de que, ao contrário do modelo clássico, a responsabilidade civil ambiental, atualmente, sofre influência direta de critérios de justiça distributiva, ou seja, o ideal moderno estabelecido após as 
revoluções liberais é insuficiente para compreender a responsabilidade civil ambienta no direito brasileiro.

\section{O DIREITO DOS DANOS COMO EXPRESSÃO DA TEORIA CORRETIVA CLÁSSICA DO DIREITO PRIVADO}

A constitucionalização do direito civil com todos os benefícios e interesses na defesa dos direitos fundamentais dos cidadãos teve como um viés negativo a retração de certas áreas. A teoria do direito privado esteve entre os debates que foram atingidos. De teoria mais importante do sistema, o direito privado se tornou secundário. Com essa mudança, há dois caminhos possíveis para o teórico do direito privado, pode-se caminhar ao isolamento, com a construção de uma teoria que simplesmente negue a mudança constitucional, ou, pode-se adaptar o campo do direito de acordo com os novos pressupostos, em pleno diálogo.

A primeira solução foi seguida por aqueles que não queriam aceitar as mudanças e muitas vezes traziam consigo outros ideais que levavam a uma valorização do passado. A proteção da propriedade e a valorização da família tradicional são dois destes elementos. De outra via, a segunda solução, a tentativa de realizar um debate entre as áreas específicas e o direito constitucional, acabou se realizando de maneira a reduzir a construção do direito civil e simplesmente se limitou a repetir muitas vezes o que já era dito na esfera do direito público constitucional. A esfera do justo, da construção do politicamente ou moralmente adequado, seria o direito constitucional. Ao direito civil caberia apenas a reprodução destes ideais. Nesse contexto de aceitação direta do direito constitucional, que trouxe claros avanços ao direito privado, como a ampliação do conceito de família, foi construído o direito civil após o século XX no Brasil.

O problema que surgiu com esta transição foi o abandono dos teóricos civilistas tradicionais sem a substituição deles por versões oxigenadas de especialistas do campo. Porém, surgem no país, após os anos 2000, diversos teóricos do direito privado que trouxeram um novo interesse em debater os fundamentos do direito privado e sua relação com outros campos como a justiça. Exemplos importantes dessa mudança são Claudio Michelon, Catarina Barbieri, Ronaldo Porto Macedo Jr. e Rafael Dresch. Esses autores tentaram vincular os debates do direito privado além dos clássicos já estabelecidos, bebendo da fonte dos debates filosóficos do direito privado principalmente do contexto anglo-saxão. 
É por meio deste cenário de debate que acreditamos que, a medida em que nos posicionamos em uma discussão de responsabilidade civil ambiental, precisamos delimitar de maneira clara os contornos de teoria do direito privado que fundamentam a análise. Mais ainda, precisamos estabelecer quais as medidas e elementos básicos que o direito dos danos requer para fornecer respostas adequadas aos problemas próprios da responsabilidade civil ambiental e nesse aspecto a filosofia da responsabilidade é central na construção de novos modelos teóricos ou de novas interpretações dos modelos já existentes.

Como enunciado por Papayannis e Fredes (2018, p. 2), os problemas de responsabilidade civil reclamam a uma questão bem clara: "por que A deve reparar um dano que causou a B?", assim como, “quem paga e por quê?”. Pode-se lidar com esta questão de diversas maneiras. Uma delas é manter a sua visão limitada pelo direito, apenas às respostas mais óbvias e diretas. Porém, pode-se levantar outras possibilidades, de como fundamentar o problema.

A pergunta implícita na questão "quem paga e por quê" está em saber qual é a justificação para aquele ato. Por que é justo fazer que a pessoa X pague para a pessoa Y? Para a nossa visão marcada pela modernidade e seu direito concentrado no Estado, a resposta parece óbvia: basta observar o que a jurisprudência afirma. Porém, na filosofia da responsabilidade civil, esta solução não basta. Podemos refletir e propor interpretações do justo e de como o modelo jurídico pode se tornar mais ou menos justo de acordo com as soluções que escolhemos.

Isso nos introduz que os problemas afetos à teoria da responsabilidade civil estão sob o olhar atento e imprescindível das teorias da justiça. Enquanto áreas como o direito penal bradam e emocionam com a justiça ou injustiça de suas decisões, muitas vezes o direito privado é esquecido, jogado para fora da área de análise. Assim o é por que as respostas aos questionamentos acima quase sempre reclamam questões de alocação de recursos, meritocracia, distribuição ou reparação de bens da vida. Perceber estes elementos, é perceber que o direito privado pode ser outro e que essas mudanças podem afetar outros campos, como, por exemplo, o direito ambiental.

Nesse contexto, os olhares filosóficos das teorias da justiça nos encaminharão para duas possibilidades. A primeiro delas é a do viés filosófico analítico. O debate da filosofia do direito privado é fortemente marcado pelo contexto anglo-saxão. Existem vários motivos para este enfoque, alguns teórico-históricos e outros não. Em primeiro caso, é importante notar que 
o direito privado anglo-saxão, marcado pelo seu sistema jurídico em common law, permite uma abertura ao debate não estatal que possibilitou que a dogmática e a prática construíssem interpretações acerca de conceitos valiosos para nós, como o de responsabilidade. Contudo, junto com este debate, os autores vão trazer outros elementos, até mesmo políticos, como o liberalismo. Logo, variados autores de teoria do direito privado interpretam a análise dos institutos privatistas por meio de uma teoria da justiça com pano de fundo na teoria política do liberalismo, especificamente no contexto de uma teoria liberal igualitária ${ }^{6}$.

A segunda possibilidade, é muito mais histórica e se relaciona com a história do direito privado no contexto que vai além do debate anglo-saxão. A história do direito ocidental, principalmente continental, é marcada pela influência de certos elementos da tradição. A religião foi um deles. Mesmo o maior ímpio não pode negar a influência da igreja no direito medieval e até mesmo em alguns países durante a modernidade.

Porém, além da religião, outros elementos marcantes são a cultura grega, e os debates franceses e germânicos sobre o direito. Da cultura grega, elemento que nos interessa mais no momento, é recorrente que os conceitos clássicos de Aristóteles, refinados por Tomás de Aquino, sejam utilizados para uma pretensão de explicação dos termos de responsabilidade civil, aqui especificamente, ambiental.

Tanto é assim que Barbieri (2019, p. 91) contextualiza o binômio justiça corretiva e justiça distributiva como um dos três pares de problemas atuais da responsabilidade civil. $\mathrm{O}$ que faz muito sentido, se não ignorarmos a história do direito privado e a força que estes conceitos tiveram em sua formação. Entre essas influências, o já pronunciado uso do binômio justiça corretiva e justiça distributiva.

Estes conceitos, que encontram seus ápices em momentos diferentes, retornam posteriormente e voltam a ser utilizados para pensar o justo. Este é um ponto que a genialidade de autores como Aristóteles precisa ser louvada. Ele não acertou na complexidade. Foi ao colocar a questão da justiça corretiva e da justiça distributiva de forma simples, que ele fez com que não fosse possível prescindir do par de conceitos nos moldes aristotélicos, como já apontam Papayannis e Fredes (2018, p. 3), uma vez que a distinção entre justiça distributiva e corretiva estabelece em certo sentido os modos de ordenação social, podendo em linhas gerais delimitar o direito público e o direito privado.

\footnotetext{
${ }^{6}$ Sá (2018) faz um recorte parecido em relação ao instituto de propriedade, numa leitura entre Amartya Sen e John Rawls. No mesmo sentido é o trabalho de Muñoz (2015) em relação ao direito contratual. Entendemos que a responsabilidade civil pode ser vista nos mesmos moldes.
} 
Mas antes de seguir o raciocínio, precisamos pensar exatamente o que queremos dizer com justiça e com justiça distributiva e corretiva. Para dimensionar o raciocínio entre essas definições, utilizaremos o conceito de Muñoz (2015, p. 18) para quem a justiça seria uma espécie de virtude moral com função de estabelecer critérios de alocação de recursos. Essa alocação, por seu turno, seria decisiva para a distinção dos conceitos de justiça, cujo o impacto das escolhas é significativo para o tratamento filosófico de institutos jurídicos de direito público e de direito privado.

A justiça corretiva ${ }^{7}$, ou comutativa, segundo Aristóteles (2009, p. 153-154), seria, então, uma forma especialmente materializada em relações voluntárias ou involuntárias (exemplo da responsabilidade civil extracontratual), em que os critérios de justiça estariam dispostos de acordo com uma igualdade aritmética. Seria uma forma de igualdade por equivalência, pouco importando as qualidades (ou méritos) do indivíduo. Os critérios avaliativos para o uso da justiça corretiva seriam de acordo com a situação que ela tenta estabelecer. No caso da justiça corretiva para trocas econômicas, por exemplo ela precisaria avaliar os valores das trocas que estão na relação jurídica. Não é por outro motivo, que a superação da visão negativa do lucro na transição da idade média para a modernidade, também envolveu a superação da justiça corretiva, pelo menos, em sua forma mais tradicional (que os produtos tinham valores fixos e que o justo envolvia apenas a troca por esses valores, sem o lucro). Dessa forma, em caso de desequilíbrio entre dois pares, a justiça corretiva tentaria reestabelecer o equilíbrio e mitigar as perdas em detrimento dos ganhos.

De outro turno, a noção de justiça distributiva, de acordo com Aristóteles (2009, p. 152-153), é traduzida pela noção de proporção entre alocação de bens e/ou encargos dentro de uma comunidade. O justo seria um meio entre dois extremos. Aqui, de acordo com a alocação de um bem ou de um encargo, existem critérios diferentes de alocação. No caso de um encargo, por exemplo, se analisará a culpa da pessoa e a sua capacidade de assumir este encargo. No caso de um benefício, que nos interessa de forma especial, segundo o qual as qualidades do indivíduo importam e deve-se almejar uma igualdade proporcional a esse fato,

\footnotetext{
${ }^{7}$ Importante mencionar o entendimento de Papayannis em relação a justiça corretiva, uma vez que o autor defende que os termos clássicos da justiça corretiva aristotélica foram paulatinamente deixados de lado no contexto do teórico dos anos de 1970 e 1980, voltando a discussão mais recentemente para entender o contexto dos institutos de direito privado (2016, p. 69). Segundo o autor, há ainda três versões de justiça corretiva estabelecida por autores de direito privado ao longo do século XX como o próprio Ernest Weinrib e Jules Coleman, seriam: i) concepção anuladora; ii) concepção relacional, e; iii) concepção mista (PAPAYANNIS, 2016, p. 82). Apesar de um modelo distinto do clássico, as visões debatem os termos de justiça com base tanto em Aristóteles, quanto em Immanuel Kant.
} 
trabalhando assim com dois critérios, o mérito e a necessidade. Não é por outro motivo que ao trabalhar a justiça distributiva, Aristóteles traz o exemplo da flauta para sua explicação, no caso de selecionar quem deve receber uma flauta, não se deve pensar apenas na necessidade, deve-se levar em conta quem vai produzir a maior felicidade e quem é melhor em tocar a flauta (logo percebe-se um motivo que os utilitaristas tem para pensar o utilitarismo é uma tese que já existe mesmo antes de sua criação formal).

Por fim, o conceito também pode ser visto em três sentidos por Muñoz (2015, p. 19): a) alocação de recursos que propicie condições/bens materiais para uma vida equilibrada; b) alocação propicie maior riqueza para a sociedade como um todo, e; c) alocação que propicie riqueza de forma homogênea.

Ante a essa clássica divisão, costumou-se a associar a justiça distributiva como preponderante na relação entre Estado-indivíduo, muito mais vinculada aos temas de direito público, como direito administrativo, constitucional e tributário. Por sua vez, o viés corretivo estaria relacionado às relações entre indivíduo-indivíduo, isto é, seria campo para o ramo do direito privado, como o direito civil, empresarial ou consumidor.

Tendo isso como pressuposto, Zamora (2015, p. 2547) menciona que o conceito de justiça corretiva, na visão de grande parte dos teóricos do direito dos danos, parece uma ideia simples e elegante, uma vez que, numa formulação básica, a responsabilidade civil extracontratual é uma retificação de uma situação danosa, a qual exige que o indivíduo vulnerado seja compensado na exata medida do dano, sem considerar os recursos ou méritos dos sujeitos envolvidos. $\mathrm{O}$ argumento central dessa ideia é forte ainda hoje e foi desenvolvido, ao longo da história, por autores libertários, kantianos e pragmáticos.

Para entendermos mais a influência da justiça corretiva nos institutos de direito privado, especialmente no direito dos danos, Dresch (2013, p. 20) nos explica que a justiça corretiva foi se desenvolvendo no intuito de preservar uma igual liberdade. Tendo isso em vista, o papel do Estado seria unicamente o de garantir uma correção entre os privados envolvidos em determinada relação.

Nessa mesma linha, Weinrib ${ }^{8}$ compreende os institutos jusprivatistas como parte de uma estrutura relacional formal caracterizada pela correlatividade entre direitos e deveres de

\footnotetext{
${ }^{8}$ Ernest Weinrib é professor da Universidade de Toronto (Canadá) e um dos grandes defensores do formalismo no direito privado. Uma de suas principais teses é a crítica à responsabilidade objetiva, que considera incompatível com a racionalidade da responsabilidade civil, que seria de justiça corretiva (Barbieri, 2019). Segundo Dresch (2013, p. 31), o formalismo defende a ideia central de que os institutos de direito privado
} 
proteção da personalidade dos participantes (DRESCH, 2013, p. 34). A relação entre indivíduos seria correta, então, se o liame entre as duas partes fosse racional entre si, sem considerações externas (como as de justiça distributiva ou econômicas). Em outras palavras, os termos corretivos se justificariam em busca de uma preservação de igual liberdade estritamente formal, individualista e voluntarista.

O pragmatismo de Jules Coleman, por seu turno, propunha uma visão holística da responsabilidade civil em termos de justiça corretiva (DRESCH, 2013, p. 44), em que o instituto apenas se explicaria em termos de justiça corretiva, mas que poderia, no caso concreto, ter influências externas. Para Coleman a justiça corretiva teria um núcleo, mas muitos casos não seriam explicados pela própria justiça corretiva em si (ZAMORA, 2015, p. 2570).

Conclui Zamora (2015, p. 2447) que, ainda que os autores discordem da relação aos termos específicos da responsabilidade civil (como se é baseada na culpa ou no risco), foi (e é) muito difundido entre os principais autores da teoria do direito privado que os problemas afetos ao direito dos danos é um problema cujos termos estão propostos através da justiça corretiva. O próprio Dresch (2009, p. 103-104) afirma que a responsabilidade civil nos termos inicialmente propostos pelo ordenamento jurídico brasileiro (numa leitura eminentemente constitucional) tem uma matriz geral de justiça corretiva.

Os argumentos que imputam o sistema como de bases corretivas não estão sem razão e têm como pano de fundo uma teoria política e jurídica por trás (desde teorias libertárias a teorias liberais-igualitárias). A tradição filosófica ocidental, portanto, é incisiva nesse sentido e a responsabilidade civil ambiental, por estar inserida no mecanismo de direito privado, a priori, estaria enquadrada nesse modelo.

\section{A RESPONSABILIDADE CIVIL AMBIENTAL COMO EXPRESSÃO DA JUSTIÇA DISTRIBUTIVA}

Se, por um lado, os institutos de direito privado, especialmente o direito dos danos, estão associados à noção clássica de autonomia da vontade entre particulares, e

possuem uma racionalidade própria e independente do direito público, materializada por uma forma estruturada e interna, que adota a justiça corretiva aristotélica e a perspectiva jurídica kantiana, pois busca uma explicação de direitos e deveres entre indivíduos a partir da racionalidade própria da relação em si, de modo a ser incompatível com qualquer consideração externa como eficiência econômica ou distribuição de recursos. 
consequentemente, orientados por um reequilíbrio ex ante entre as partes, por outro lado, há uma clara tendência filosófica que encaminha os institutos relacionados à responsabilidade civil, especialmente a ambiental, para uma possível conclusão em contrário, isto é, que, em última análise, corporifica conceitos de justiça distributiva em suas práticas ${ }^{9}$.

Não obstante a intuitiva distinção já introduzida na seção anterior de que a justiça corretiva está mais ligada historicamente às relações privadas (indivíduo-indivíduo), enquanto a justiça distributiva está mais relacionada entre as relações de públicas (Estado-indivíduo), Muñoz (2015, p. 20) faz uma defesa enfática no sentido de que esses conceitos foram se misturando ao longo da era moderna, e as definições de justiça distributiva foram, cada vez mais, incorporados nas relações entre indivíduos, especialmente a partir da constitucionalização do direito civil e da incorporação de cláusulas gerais.

A autora cita como caso hipotético, amplamente mencionado por autores norteamericanos, a situação de determinada empresa do ramo petroleiro que, através de uma investigação geológica, descobre uma vasta área de potencial energético no interior de uma fazenda de determinado indivíduo. Sem mencionar a informação privilegiada, a empresa entra em negociação com o fazendeiro e adquire a propriedade pelo preço de mercado similar a das outras propriedades da região, sem sopesar o potencial energético (MUÑOZ, 2015, p. 16). Explica Muñoz, com a ressalva de que o caso não seria aplicável ao direito brasileiro em virtude da propriedade das reservas minerais ser da União, que esse negócio jurídico seria passível de anulação ou indenização correspondente e que assim o seria pela tendência explicável pelos termos de justiça distributiva corporificada em ordenamentos constitucionais modernos, como o brasileiro.

Casos como o explanado seriam diversificados no contexto contratual brasileiro. Tal seria, por exemplo, nas normativas de relações de trabalho, limites à usura em mútuos não financeiros, garantias irrenunciáveis em relações locatícias, inversão do ônus probatório dos contratantes, possibilidade de propositura coletiva de demandas (MUNOZ, 2015, p. 18-19). Se, portanto, o instituto privatista por excelência, como o direito contratual pode ser

\footnotetext{
${ }^{9}$ Importante destacar que há uma grande discussão sobre a funcionalização do instituto através da análise econômica do direito, importante teoria do direito privado proeminente no século XX e ainda muito debatida. A AED, sigla para a expressão em inglês Economic Analysis of Law ou Law and Economic, é um movimento teórico encampado por autores como Guido Calabresi, Richard Posner, Steven Shavell e Ronald Coese, que buscava entender os institutos do direito (especialmente os de direito privado como os contratos e a responsabilidade civil extracontratual), como instrumentos consequencialista, para garantir o máximo de bem estar à maioria possível de indivíduos (DIAS, 2018). O direito, portanto, seria uma ferramenta dos instrumentos econômicos e deveria ser pautado no princípio da eficiência.
} 
enxergado como expressão de justiça distributiva, parece-nos intuitivo, a contrario sensu, que a o direito dos danos, especialmente a responsabilidade civil ambiental possa seguir essa lógica.

É numa linha semelhante que se encaminha o raciocínio de Dresch. Conforme mencionado no tópico antecedente, o autor entende que a responsabilidade civil brasileira se propõe a ser corretiva e formalista. Entretanto, numa leitura mais propensa à doutrina consumerista, o nosso sistema permite inserções notadamente de justiça distributiva no sistema de responsabilidade civil, e que os fins perseguidos pelo instituto, a depender do caso, podem ser variados (DRESCH, 2009, p. 103). Desse modo, haveria a coexistência de um sistema subjetivo com fundamentos formalistas ao mesmo tempo de um sistema distributivo com fundamentos funcionalistas ${ }^{10}$.

Apesar de ser uma análise mais próxima do direito consumerista, encontramos um endosso teórico não definitivo, mas tendente a esse raciocínio, a medida em que avançamos nos escritos ambientais. É nesse sentido que Leal (2014, p. 15) sugere que a responsabilidade por dano ambiental cede a uma disposição distributiva e confronta o modelo de justiça corretiva em seus elementos principais, quais sejam, dano, causalidade e responsabilidade individual. Segundo a autora, portanto, esses elementos perderam proeminência mais recentemente.

No sentido do que sugerem Dresch e Leal, há espaço para algumas ponderações importantes, dado que, especialmente quando se fala em responsabilidade objetiva, a justiça corretiva não fornece muitas das respostas para casos representativos. Tal embaraço surge principalmente em dois casos, segundo Zamora (2015, p. 2573): a) não é claro quando surge o dever de indenizar, por consequência não se tem subsídios para fazer a distinção entre os elementos corretivos/distributivos; b) a própria noção de causalidade é complexa, o que ocasionaria também problemas de distinção entre responsabilidade com culpa e responsabilidade sem culpa, por exemplo.

Diante de problema, Zamora sugere que os teóricos clássicos, como Weinrib e Coleman, se recusam a enfrentar o problema, e que o objetivo atual da teoria do privado, especialmente no contexto da américa latina, consiste em entender a justiça corretiva como

\footnotetext{
${ }^{10} \mathrm{O}$ funcionalismo, nos termos aqui explanados, entende que o direito privado oferece instrumentos a serem utilizados especialmente para alcançar fins econômicos sociais e desejáveis, dada a realidade social. A responsabilidade civil por exemplo seria um instrumento para estabelecer uma distribuição eficiente de recursos ou a proteção de um direito social (DRESCH, 2013, p. 100).
} 
modelo apto explicar adequadamente a responsabilidade objetiva e suas considerações distributivas (ZAMORA, 2015, p. 2573). Assim, as questões econômicas e de justiça distributiva são hoje fundamentais para entender as repercussões que se materializam, especialmente no contexto de danos difusos/coletivos.

Talvez o exemplo mais significativo para nossos propósitos seja o de Papayannis, o qual também vai se contrapor à doutrina clássica. Defende o autor que há nos ordenamentos jurídicos o estabelecimento de direitos e deveres de indenização, cuja definição é variável e dependente da convenção de cada comunidade jurídica específica (PAPAYANNIS, 2016, p. 143). Tais direitos e deveres de indenização estabeleceriam os critérios de vulneração/reparação dos direitos primários dos indivíduos, ocasião em que o sistema poderia optar por um sistema de culpa, de reponsabilidade objetiva, ou mesmo de não responsabilização (PAPAYANNIS,2016, p. 143).

Esses direitos e deveres de indenização, segundo Papayannis, estariam dentro do espectro de bens primários no sentido ralwsiano, uma vez que tais direitos seriam indispensáveis para que o indivíduo possa seguir o seu plano de vida (2016, p. 145). Ou seja, tais direitos e deveres se encontram em posições iguais a direitos e deveres primários "clássicos" como propriedade, liberdade e privacidade. Como os bens primários sofrem inegável influência de critérios distributivos no contexto de uma teoria da justiça, então, teríamos que a definição dos modos em que um indivíduo seria responsabilizado é influenciada pela justiça distributiva. Portanto, nesse raciocínio, a responsabilidade civil também reclama de forma inevitável atuação da justiça distributiva.

Seguindo o argumento, não obstante uma prévia distribuição de bens através dos direitos e deveres de indenização, o estabelecimento em concreto da restituição ante uma violação seria conteúdo, entretanto, da justiça corretiva (PAPAYANNIS, 2010, p. 192).

A relação entre responsabilidade civil e justiça corretiva seria contingente, uma vez que os padrões de direitos e deveres de indenização existiriam ainda que sem as determinações corretivas (PAPAYANNIS, 2010, p. 235). Em resumo, entende o eminente doutrinador que a responsabilidade civil é um sistema distributivo em si, que é auxiliado/reforçado pela justiça corretiva (ambos princípios independentes e autônomos).

Um dos argumentos decisivos de Papayannis (2016, p. 139) para os nossos encaminhamentos é que, apesar de não necessário, os padrões de justiça corretiva auxiliam o 
estabelecimento da responsabilidade especialmente na busca de uma justiça particular, especialmente na divisão de responsabilidade.

Poderia, portanto, haver um sistema de responsabilidade sem justiça corretiva, embora não seja o ideal em termos de justiça igualitários. Encontramos uma possível repercussão desse atributo justamente em decisões recentes do Superior Tribunal de Justiça em relação à atribuição de responsabilidade civil ambiental.

Nos diz o STJ que a atribuição de responsabilidade por ilícitos ambientais é uma obrigação propter rem, isto é, os danos ambientais podem ser imputados a outrem alheio à relação originária (AgRg. no REsp. 1206484/SP, Rel. Min. Humberto Martins, 2. ${ }^{\text {a }}$ T. j. 17.03.2011, DJe 29.03.2011).

No caso discutido pela Corte Superior, por intermédio do Recurso Especial $\mathrm{n}^{\circ}$ 1206484/SP, de relatoria do Ministro Humberto Martins, discutia-se sobre a incidência ou não de responsabilidade civil extracontratual aos indivíduos que adquiriram determinado propriedade rural. Os adquirentes, em sede defesa nos autos processuais do Recurso Especial em questão, alegaram inexistência de obrigação de reparar, tendo em vista que não foram os autores diretos do ilícito. Apenas adquiriram o imóvel rural nas exatas condições em que estava. Portanto, pugnaram pela improcedência da responsabilização. O Superior Tribunal de Justiça, por sua vez, decidiu que não assistia razão os argumentos dos recorrentes, dado que a responsabilidade civil ambiental é do tipo objetiva e propter rem, incidindo sobre titulares do bem imóvel, detentores e exploradores, pouco importando quem efetivamente causou o dano ambiental em concreto.

Essa decisão segundo Farias, Rosenvald e Netto (2017, p. 505-506) é complicada em termos de filosofia do direito privado, tendo em vista que se atribui a causalidade a outrem como sendo supostamente o segurador universal. Essa atribuição de responsabilidade, em nossa leitura dos argumentos de Papayannis, seria uma típica atribuição de justiça distributiva, mas não seria de matriz corretiva. Faltaria justiça particular no caso concreto, uma vez que não há correlação evidente entre a conduta do suposto agente danador e a efetiva lesão ao meio ambiente causada.

Cabe ainda mencionar a decisão proferida pelo STJ no âmbito do Recurso Especial $\mathrm{n}^{\circ}$ 1.114398-PR, de Relatoria do Ministro Sidnei Beneti. O caso é relativo a um acidente ocorrido no Porto de Paranaguá. Um navio de uma empresa petroleira estatal acabou por despejar na região do porto a Nafta, determinado material químico. O fato ocorreu em virtude 
de um deslizamento de terras imprevisível na região. Por seu turno, o derramamento acabou por inviabilizar a pesca na região. Certo indivíduo, pescador e diretamente prejudicado pelo acidente, ajuizou judicialmente ação de danos morais e materiais em face da petroleira. A empresa estatal, de outro lado, argumentou que não teria responsabilidade no caso, tendo em vista que teria concorrido dolosa ou culposamente para o evento danoso. A corte superior entendeu favoravelmente à condenação em danos morais e materiais da empresa, ancorando seu entendimento na responsabilidade civil ambiental, especificamente com base na teoria do risco integral, que propõe uma causalidade absoluta, segundo a qual o poluidor (produtor do evento danoso) será condenado ainda que tenha agido em legítima defesa/estado de necessidade ou ainda sob a incidência de caso fortuito/força maior/culpa exclusiva de terceiro (FARIAS; NETTO; ROSENVALD, 2017, p. 502).

Frise-se, por exemplo, que neste caso o STJ estaria estabelecendo direitos e deveres de indenização nos moldes do que propõe Papayannis (2016, p. 144 e ss.). Assim, os tribunais e os juízes em geral, quando intentam operações argumentativas e interpretativas, realizam, em última instância, o estabelecimento de direitos e deveres de indenização. A corte superior, no fim das contas está estabelecendo um fundamento de imputação do dano puramente baseada em critérios funcionalistas, numa leitura evidente de critérios de justiça distributiva.

A partir do exposto, temos que intuitivamente os termos distributivos podem ser considerados numa leitura de responsabilidade civil, e especialmente de responsabilidade ambiental. Há argumentos fortes nesse sentido.

\section{CONCLUSÃO}

A discussão que se propõe o presente trabalho está longe de resolução pacífica. Os pressupostos filosóficos dos direitos dos danos são controvertidos entre os diversos autores, cuja maioria se encontra no contexto anglo-saxão. Isso torna o debate ainda mais complexo e não menos interessante.

De outra via, se o direito dos danos prospecta uma importante discussão no âmbito do direito privado, é inegável que o contexto atual da responsabilidade civil se tornou também mais complexo com o avanço da massificação dos danos. Nesse tempo, ante a consagração corporificada pelas constituições modernas, o direito dos danos é ramo auxiliar de uma série 
com repercussões públicas diretas e indiretas como as discussões envolvendo a proteção do meio ambiente.

Nesse aspecto, embora os termos inicialmente propostos pelo direito privado indiquem que a responsabilidade civil cuide do restabelecimento de um equilíbrio anterior entre as partes, temos que o direito brasileiro, através de sua nova matriz constitucional, bem como os tribunais brasileiros, não entendem que essa seja a lógica apropriada para a responsabilidade civil ambiental. Isso por que o tipo de responsabilidade objetiva proposto, principalmente no âmbito do Superior Tribunal de Justiça, permite uma mitigação da noção de que o trato dos danos ambientais deve seguir a lógica do mero reequilíbrio anterior, isto é, que os termos de justiça corretiva, nesse caso, precisam ser superados.

A teoria da responsabilidade civil ambiental brasileira (baseada na teoria do risco integral) nos faz inferir que os ramos desse instituto não se limitam mais a termos estritamente de direito privado. No entanto, ainda que consideremos a realidade fática, não significa que endossemos os moldes em que são aplicados a teoria do risco integral. Pelo contrário, compactuamos das críticas de Farias, Netto e Rosenvald, onde um regime de causalidade pura poderia desvirtuar os valores e a própria segurança na aplicação do instituto em análise.

De outra via, é possível uma saída pelos termos constitucionais, uma vez que a constituição federal de 1988 permite que reflitamos sobre a inflexão de uma racionalidade a priori tida como de direito público nos institutos de direito privado. Essa construção, no entanto, deve ser fruto de uma análise crítica e argumentativa, de modo que buscamos, incialmente compor o que se tem de mais proeminente no contexto latino-americano em termos de responsabilidade civil, especialmente no âmbito da repercussão ambiental. Assim, perfilhamos um entendimento de que os critérios de justiça distributiva estão marcados, de alguma maneira, na responsabilidade civil brasileira.

\section{REFERÊNCIAS BIBLIOGRÁFICAS}

AMADO, Frederico. Direito Ambiental. 7. ed. Salvador: Ed. Juspodivm, 2019.

ARISTÓTELES. Ética a Nicômaco. Livro V. Tradução, estudo bibliográfico e notas de Edson Bini. São Paulo: EDIPRO, 2009. 
BARBIERI, Catarina Helena Cortada. Filosofia e direito privado: a fundamentação da responsabilidade civil contemporânea a partir da obra de Ernest Weinrib. São Paulo:

Almedina, 2019.

BENATTI, José Heder; BRITO, Ciro de Souza; CARAMÊS, Brenda; BELUCIO, Francielcio. Bens públicos: principais categorias fundiárias. In: FISCHER, Luly Rodrigues da Cunha (coord.). Manual de direito agrário. 1. ed. Belém: UFPA, 2018.

\section{BRASIL, SUPERIOR TRIBUNAL DE JUSTIÇA (STJ). Recurso Especial no 1114398/PR} (REsp no 1114398/PR). Recorrente: Petróleo Brasileiro S A Petrobrás. Recorrido: Gabriel Correa. Rel. Min. Sidnei Beneti. Julgamento em 08 de fevereiro de 2012. Diário de Justiça, BrasíliaDF, 16 de fevereiro de 2012. Disponível em:

<https://scon.stj.jus.br/SCON/GetInteiroTeorDoAcordao?num_registro=200900679891\&dt_p ublicacao=16/02/2012 >. Acesso em: 20 mar.2021.

Recurso Especial no 1206484/SP (REsp no 1206484/SP). Recorrente: Renato Cesar Colombo e Outros. Recorrido: Ministério Público do Estado de São Paulo. Rel. Min.

Humberto Martins. Julgamento em 17 de março de 2011. Diário de Justiça, BrasíliaDF, 29 de março de 2011. Disponível em:

$<$ https://scon.stj.jus.br/SCON/GetInteiroTeorDoAcordao?num_registro=201001393516\&dt_p ublicacao=29/03/2011>. Acesso em: 20 mar.2021.

DIAS, Jean Carlos. Teorias contemporâneas do direito e da justiça. Salvador: Editora Juspodivm, 2018.

DRESCH, Rafael de Freitas Valle. Fundamentos da Responsabilidade Civil pelo Fato do Produto e do Serviço: Um Debate Jurídico- Filosófico entre o Formalismo e o Funcionalismo no Direito Privado. Porto Alegre: Livraria do Advogado, 2009.

Fundamentos do Direito Privado: Uma Teoria da Justiça e da Dignidade Humana. São Paulo: Atlas, 2013.

FARIAS, Cristiano Chaves de; NETTO, Felipe Peixoto Braga; ROSENVALD, Nelson. Curso de direito civil: responsabilidade civil. 4. ed. rev. e atual. Salvador: Ed. Juspodivm, 2017.

FREDES, Esteban; PAPAYANNIS, Diego. Filosofía del derecho privado. Madrid: Marcial Pons, 2018.

LEAL, Virgínia de Carvalho. Responsabilidade Ambiental e as Teorias de Justiça: um novo paradigma rumo à justiça ambiental distributiva? Revista Cabo dos Trabalhos, vol. 10, p. 116, 2014. Disponível em:

<https://cabodostrabalhos.ces.uc.pt/n10/documentos/3.2.5_Virginia_de_Carvalho_Leal.pdf >. Acesso em: 20. nov. 2020.

MILARÉ, Édis. Direito do ambiente. 11. ed. São Paulo: Revista dos Tribunais, 2018. 
MUÑOZ, Maria Paula Costa Bertran. Justiça e contrato: entre comutar e distribuir. São Paulo: Editora da Universidade de São Paulo, 2015.

PAPAYANNIS, Diego M. Comprensión y justificación de la responsabilidad extracontractual. 2010. Tese de Doutorado (Doutorado em Direito), 453 f., Universidad Pompeu Fabra, Departament de Dret, Barcelona, 2010.

Externado de Colombia, 2016.

EI derecho privado como cuestión pública. Bogotá: Universidad

SÁ, João Daniel. Direito de propriedade: uma análise do papel da propriedade rural no contexto da justiça distributiva. Rio de Janeiro: Lumen Juris, 2018.

ZAMORA, Jorge Luis Fabra. Filosofía de la responsabilidad extracontractual: un llamado al debate. In:SPECTOR, Ezequiel; ZAMORA, Jorge Luis Fabra (eds.). Enciclopedia de Filosofía y Teoría del Derecho - vol. 3. Ciudad de México: Universidad Nacional Autónoma de México, 2015. 